Received: December 18, 2019 Accepted: March 18, 2020

First published online: March 20, 2020

*Corresponding authors W.W.

Phone: +86-57786699659 Fax: +86-57786689771 E-mail:wangwu@wmu.edu.cn J.L.

Phone: +86-57786699659

Fax: +86-57786689771

E-mail: ljx@wmu.edu.cn

Phone: +86-57786699659

Fax: +86-57786689771

E-mail: tgq@wmu.edu.cn

${ }^{\dagger}$ These authors contributed equally to this work.

Supplementary data for this paper are available on-line only at http://jmb.or.kr.

pISSN 1017-7825 elSSN $1738-8872$

Copyright(C) 2020 by The Korean Society for Microbiology and Biotechnology

\section{Removal of Chromium (VI) by Escherichia coli Cells Expressing Cytoplasmic or Surface-Displayed ChrB: a Comparative Study}

\author{
Xiaofeng Zhou ${ }^{1 \dagger}$, Jianghui Li ${ }^{1 \dagger}$, Weilong Wang ${ }^{1}$, Fan Yang ${ }^{1}$, Bingqian Fan ${ }^{1}$, Chenlu Zhang ${ }^{1}$, \\ Xiaojun Ren', Feng Liang', Rong Cheng ', Fengying Jiang' ', Huaibin Zhou', Juanjuan Yang ', \\ Guoqiang $\operatorname{Tan}^{1 *}$, Jianxin Lyu ${ }^{1 *}$, and Wu Wang ${ }^{1 *}$
}

'Zhejiang Provincial Key Laboratory for Technology and Application of Model Organisms, School of Laboratory Medicine and Life Sciences, Wenzhou Medical University, Wenzhou 325035, Zhejiang, P.R. China

${ }^{2}$ School of Public Health and Management, Wenzhou Medical University, Wenzhou 325035, Zhejiang, P.R. China

Various genetically engineered microorganisms have been developed for the removal of heavy metal contaminants. Metal biosorption by whole-cell biosorbents can be enhanced by overproduction of metal-binding proteins/peptides in the cytoplasm or on the cell surface. However, few studies have compared the biosorption capacity of whole cells expressing intracellular or surface-displayed metal-adsorbing proteins. In this study, several constructs were prepared for expressing intracellular and surface-displayed Ochrobactrum tritici 5bvl1 ChrB in Escherichia coli BL21(DE3) cells. E. coli cells expressing surface-displayed $\mathrm{ChrB}$ removed more $\mathrm{Cr}(\mathrm{VI})$ from aqueous solutions than cells with cytoplasmic ChrB under the same conditions. However, intracellular ChrB was less susceptible to variation in extracellular conditions (pH and ionic strength), and more effectively removed $\mathrm{Cr}(\mathrm{VI})$ from industrial wastewater than the surface-displayed $\mathrm{ChrB}$ at low $\mathrm{pH}(<3)$. An adsorptiondesorption experiment demonstrated that compared with intracellular accumulation, cell-surface adsorption is reversible, which allows easy desorption of the adsorbed metal ions and regeneration of the bioadsorbent. In addition, an intrinsic ChrB protein fluorescence assay suggested that $\mathrm{pH}$ and salinity may influence the $\mathrm{Cr}(\mathrm{VI})$ adsorption capacity of $\mathrm{ChrB}$-expressing $\mathrm{E}$. coli cells by modulating the ChrB protein conformation. Although the characteristics of $\mathrm{ChrB}$ may not be universal for all metal-binding proteins, our study provides new insights into different engineering strategies for whole-cell biosorbents for removing heavy metals from industrial effluents.

Keywords: Chromium (VI), ChrB, biosorption, cytoplasmic expression, surface display

\section{Introduction}

Heavy metals are major contributors to environmental pollution and pose serious health risks to humans. Various physicochemical treatment techniques for the removal of metal contaminants have been developed; however, they are usually energy-intensive and may produce hazardous byproducts. Recently, biological treatment techniques for the removal of toxic heavy metals have attracted much attention. Some natural biomasses (such as bacteria, fungi, and algae) have been found to be highly effective in the bioaccumulation or biosorption of heavy metals. Furthermore, microorganisms can be genetically engineered to enhance their biosorption capacity through overexpression of metal-binding proteins in the cytoplasm $[1,2]$ or on the cell surface $[3,4]$. However, these two strategies (intra- or extracellular biosorption) have not been comparatively characterized.

Chromium (VI) is one of the most toxic environmental pollutants due to its mutagenic and carcinogenic properties. It is widely used in the stainless steel industry, electroplating, and in leather tanneries. Interestingly, a variety of microorganisms capable of removing $\mathrm{Cr}(\mathrm{VI})$ contamination and resistant to high levels of chromate can be isolated from heavy metal-contaminated environments. The resistance mechanisms mainly comprise efflux of chromate ions from the cytoplasm and reduction of $\mathrm{Cr}(\mathrm{VI})$ to the less toxic $\mathrm{Cr}(\mathrm{III})$ form [5]. Ochrobactrum tritici 5bvl1, isolated from chromium-contaminated wastewater, is a highly $\mathrm{Cr}(\mathrm{VI})$-resistant bacterial strain [6]. Its tolerance to high chromate concentrations is attributed to the presence of a specific transposon, TnOtChr, which harbors a group of chromate resistance genes, including $\operatorname{chr} B, \operatorname{chr} A, \operatorname{ch} r C$, and $\operatorname{ch} r F$ [7]. As a chromate efflux pump, ChrA has been suggested to extrude chromate from the cytoplasm out of the cell, thereby lowering the 
intracellular $\mathrm{Cr}(\mathrm{VI})$ concentration [7]. ChrC and $\mathrm{ChrF}$ are putative superoxide dismutases that protect cells from reactive oxygen species (ROS) [8]. ChrB was identified as a chromate-sensing transcriptional regulator of the $c h r$ operon that binds directly to the $c h r$ promoter region [9]. In this study, we constructed different Escherichia coli strains that express either cytoplasmic or surface-displayed $\mathrm{ChrB}$ and we compared their $\mathrm{Cr}(\mathrm{VI})$-adsorbing capacities. The results demonstrated that $E$. coli cells expressing surface-displayed $\mathrm{ChrB}$ were more efficient in $\mathrm{Cr}(\mathrm{VI})$ adsorption than cells expressing intracellular $\mathrm{ChrB}$. In contrast, when used for treating industrial wastewater with low $\mathrm{pH}$ and high salinity, E. coli cells expressing intracellular ChrB were more effective at adsorbing $\mathrm{Cr}(\mathrm{VI})$ than those with surface-displayed $\mathrm{ChrB}$. Therefore, our findings suggest that environmental factors, such as $\mathrm{pH}$ and ionic strength, should be considered when selecting genetically engineered microorganisms for bioremediation of heavy metals.

\section{Materials and Methods}

\section{Construction of Vectors for the Expression of Intracellular or Surface-Displayed ChrB}

An optimized gene sequence (GenBank Accession No. MN340684) coding for ChrB from O. tritici 5bvl1 (GenBank Accession No. EF469735.1) was designed by taking the codon preference of $E$. coli into consideration, and was synthesized by GenScript Biotech Corp. (China). For the constructing the plasmid construct expressing surface-displayed ChrB (pET28-lpp-ompA-chrB or pET-LOChrB), three DNA fragments encoding the Nterminal (amino acids 1-29) of prolipoprotein (Lpp) (EcoGene Accession No. EG10544), residues 45-159 of the outer-membrane protein OmpA (EcoGene Accession No. EG10669), and the optimized chrB sequence were PCR-amplified from the genomic DNA of E. coli JM109 or synthesized vector using the primers Lpp-1/Lpp-2, OmpA-1/OmpA-2, and LOChrB-1/LOChrB-2, respectively. The primers Lpp-1 and LOChrB-2 were used to join the DNA sequences by recombinant PCR. Using an In-Fusion HD Cloning Kit (Clontech, USA), the lpp-ompAchrB PCR product was subcloned into the expression plasmid pET28b (Invitrogen, USA), which had been predigested with the restriction enzymes NcoI and XhoI. To synthesize the plasmid construct expressing intracellular $\mathrm{ChrB}$, a PCR product coding for the entire $\mathrm{ChrB}$ gene was amplified using the primers ChrB-1/ChrB2 and was cloned into NcoI/XhoI-digested pET28b to generate the plasmid pET-ChrB. A plasmid construct expressing ChrB with a C-terminal His-tag (pET-ChrB-His) was constructed in a similar manner, except that ChrB-2-His (in which the stop codon was removed) was used as the downstream primer. All primers used are listed in Table S1 in the Supplementary Material.

\section{Induction and Purification of ChrB Protein}

E. coli BL21(DE3) cells containing the plasmid pET-ChrB-His (pET-ChrB-His/BL21) were grown in LuriaBertani (LB) medium to an optical density at $600 \mathrm{~nm}\left(\mathrm{OD}_{600}\right)$ of $0.6-0.7$. Then, $200 \mu \mathrm{M}$ isopropyl $\beta$-Dthiogalactoside (IPTG) was added to induce protein expression at $25^{\circ} \mathrm{C}$ for $24 \mathrm{~h}$. His-tagged $\mathrm{ChrB}$ (ChrB-His) was purified using a Ni-agarose column (Qiagen, Germany) as described by Branco and Morais [9], followed by desalting on a HiTrap desalting column ( $5 \mathrm{ml}$, GE Healthcare, USA) to remove the imidazole. The purity of the purified protein was $>95 \%$ judging from the SDS-PAGE gel stained with Coomassie brilliant blue. The protein concentration of purified ChrB-His was measured at $280 \mathrm{~nm}$ using an extinction coefficient of $34.05 \mathrm{~cm}^{-1} \mathrm{mM}^{-1}$.

\section{Chromium Content Measurement}

Protein samples were digested and cell suspensions were lysed by microwave digestion before the analysis of chromium contents, whereas aqueous solutions were analyzed directly. The total Cr content was determined by inductively coupled plasma mass spectrometry. The concentration of $\mathrm{Cr}(\mathrm{VI})$ in these samples was measured by colorimetry using 1,5-diphenylcarbazide as an indicator [10]. The $\mathrm{Cr}(\mathrm{III})$ concentration was calculated by subtracting the $\mathrm{Cr}(\mathrm{VI})$ concentration from the total $\mathrm{Cr}$ concentration.

\section{SDS-PAGE/Western Blot Analysis of Intracellular and Surface-Displayed ChrB}

E. coli BL21(DE3) cells expressing intracellular ChrB without His-tag (pET-ChrB/BL21) or surface-displayed ChrB (pET-LOChrB/BL21) were grown in $\mathrm{LB}$ medium at $37^{\circ} \mathrm{C}$ to an $\mathrm{OD}_{600}$ of $0.6-0.7$, and then, protein expression was induced by the addition of $200 \mu \mathrm{M}$ IPTG. After a $24-\mathrm{h}$ incubation at $25^{\circ} \mathrm{C}$, the cells were harvested and resuspended in PBS at an $\mathrm{OD}_{600}$ of 10 . Expression of cytoplasmic and surface-displayed ChrB was detected by SDS-PAGE and western blotting using an anti-ChrB monoclonal antibody (produced by GenScript Biotech Corp.). To verify the surface display of $\mathrm{ChrB}$, cells were treated with trypsin $(200 \mu \mathrm{g} / \mathrm{ml}$ final $)$ at $37^{\circ} \mathrm{C}$ for $1 \mathrm{~h}$. The reaction was stopped by washing the cells twice with $\mathrm{PBS}$, and ChrB was then analyzed by SDS-PAGE and western blotting. Band intensity on the SDS-PAGE gel or western blot film was analyzed using ImageJ software.

\footnotetext{
Determination of $\mathrm{Cr}$ (VI) Adsorption Capacity of E. coli Expressing Intracellular or Surface-Displayed ChrB

E. coli cells (pET/BL21, pET-ChrB/BL21, and pET-LOChrB/BL21) were grown in LB medium at $37^{\circ} \mathrm{C}$ to an $\mathrm{OD}_{600}$ of $0.6-0.7$, and then, protein expression was induced by the addition of $200 \mu \mathrm{M}$ IPTG. The pET/BL21 and pET-LOChrB/BL21 cells were then incubated at $25^{\circ} \mathrm{C}$ for $24 \mathrm{~h}$, whereas the pET-ChrB/BL21 cells were harvested after $6 \mathrm{~h}$ (pET-ChrB-6h/BL21) or $24 \mathrm{~h}$ (pET-ChrB-24h/BL21) of incubation. The cells were washed with deionized water at least three times and then resuspended in $200 \mathrm{ml}$ of water containing $\mathrm{Cr}^{6+}(0,0.005,0.025$, $0.125,0.5,1.0,2.5$, and $5.0 \mathrm{mM}$, respectively) at $\mathrm{OD}_{600}=10$, and incubated at $25^{\circ} \mathrm{C}$ for $4 \mathrm{~h}$. Then, the cells were harvested by centrifugation and analyzed for $\mathrm{Cr}(\mathrm{VI})$ content as described above. $\mathrm{Cr}(\mathrm{VI})$ adsorption capacity $(\mu \mathrm{mol} / \mathrm{g})$ was defined as the amount of $\mathrm{Cr}(\mathrm{VI})$ bound per gram (dry weight) of bacterial cells, which can be measured after lyophilization.
} 
To further verify $\mathrm{Cr}$ (VI) removal capability, IPTG-induced E. coli cells (pET/BL21, pET-ChrB-6h/BL21, pETChrB-24h/BL21, and pET-LOChrB/BL21) were resuspended in $0.5 \mathrm{mM} \mathrm{Cr}^{6+}$ solution $(200 \mathrm{ml}$, final cell densities at $\mathrm{OD}_{600}=2,5$, and 10) and incubated at $25^{\circ} \mathrm{C}$. Cell suspensions were collected every $30 \mathrm{~min}$ for $4 \mathrm{~h}$ and centrifuged, and $\mathrm{Cr}(\mathrm{VI})$ concentrations in the supernatants were determined.

\section{Comparison of $\mathrm{Cr}(\mathrm{VI})$ Resistance of $E$. coli Expressing Intracellular or Surface-Displayed ChrB}

Overnight cell cultures (pET/BL21, pET-ChrB/BL21, and pET-LOChrB/BL21) were diluted 1:100 in fresh LB medium supplemented with kanamycin $(50 \mu \mathrm{g} / \mathrm{ml})$ and $\mathrm{Cr}^{6+}$ solution $(0.001,0.01,0.05,0.1,0.25,0.5,1.0,2.5,5.0$, or $10 \mathrm{mM}$ final). IPTG $(100 \mu \mathrm{M})$ was added to induce $\mathrm{ChrB}$ expression. Cell samples were adjusted to an $\mathrm{OD}_{600}$ of 0.02 and then grown at $25^{\circ} \mathrm{C}$ with vigorous shaking $(250 \mathrm{rpm})$ for $12 \mathrm{~h}$. Then, the cell density was measured again.

Effect of pH and Salinity on the Cr(VI) Adsorption Capacity of E. coli Expressing Intracellular or SurfaceDisplayed ChrB

IPTG-induced E. coli cells (pET-ChrB-24h/BL21 and pET-LOChrB/BL21) were treated with $5 \mathrm{mM} \mathrm{Cr}^{6+}$ in $200 \mathrm{ml}$ of Tris buffers with different $\mathrm{pH}$ values $(2,3,4,5,6,7,8,9$, and 10) or different concentrations of $\mathrm{NaCl}(0$, $0.2,0.4,0.6,0.8,1.0,1.2$, and $1.4 \mathrm{M}, \mathrm{pH} 7)$. All cell suspensions were adjusted to $\mathrm{OD}_{600}=10$. After $4 \mathrm{~h}$ of incubation at $25^{\circ} \mathrm{C}$, the $\mathrm{Cr}(\mathrm{VI})$ adsorption capacity of each cell sample was analyzed.

Removal of $\mathrm{Cr}(\mathrm{VI})$ from Industrial Wastewater by E. coli Expressing Intracellular or Surface-Displayed ChrB

A total of 12 wastewater samples were collected from chromium electroplating factories or tanneries located in the LongWan industrial district of Wenzhou (Southeast China). The samples were centrifuged $(12,000 \times g$, $10 \mathrm{~min}$ ) to remove any undissolved particles, and the supernatants were transferred to new tubes for the $\mathrm{Cr}(\mathrm{VI})$ removal experiment. Before treatment with E. coli cells, the $\mathrm{Cr}(\mathrm{VI}) / \mathrm{Cr}(\mathrm{III})$ concentration, $\mathrm{pH}$, and total dissolved solid (TDS) level of each sample were measured. TDS was determined using a gravimetric method as described previously [11]. E. coli cells expressing surface-displayed ChrB (pET-LOChrB/BL21) or intracellular ChrB (pET$\mathrm{ChrB}-24 \mathrm{~h} / \mathrm{BL} 21)$ were suspended directly in the water samples $\left(50 \mathrm{ml}, \mathrm{OD}_{600}=50\right)$. After $4 \mathrm{~h}$ of incubation at $25^{\circ} \mathrm{C}$, the cells were removed by centrifugation $(12,000 \times g, 10 \mathrm{~min})$. The $\mathrm{Cr}(\mathrm{VI}) / \mathrm{Cr}(\mathrm{III})$ concentrations in the treated wastewater samples (supernatant fractions) were analyzed as described above.

\section{Desorption of $\mathrm{Cr}(\mathrm{VI})$ and Regeneration of $E$. coli Expressing Intracellular or Surface-Displayed ChrB}

To test the regeneration capability of E. coli cells expressing intracellular or surface-displayed $\mathrm{ChrB}$ for $\mathrm{Cr}(\mathrm{VI})$ adsorption, cells expressing intracellular or surface-displayed $\mathrm{ChrB}$ (induced for $24 \mathrm{~h}, \mathrm{OD}_{600}=10$ ) were treated with $5 \mathrm{mM} \mathrm{Cr}{ }^{6+}$ in Tris buffer ( $\mathrm{pH}$ 7.0) for $4 \mathrm{~h}$. The $\mathrm{Cr}(\mathrm{VI})$-treated cells were collected by centrifugation and

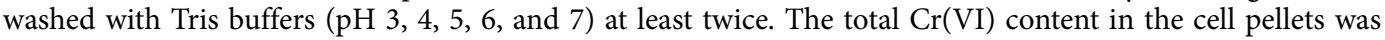
measured, and the amount of $\mathrm{Cr}(\mathrm{VI})$ desorbed was calculated as the difference between the total $\mathrm{Cr}(\mathrm{VI})$ contents of the $\mathrm{Cr}(\mathrm{VI})$-treated cells before and after washing. After $\mathrm{Cr}(\mathrm{VI})$ desorption at the optimal $\mathrm{pH}$, cells were treated with $5 \mathrm{mM} \mathrm{Cr}^{6+}$ (in Tris buffer, $\mathrm{pH}$ 7.0) and were again analyzed for $\mathrm{Cr}(\mathrm{VI}$ ) adsorption ability, which was determined as the difference between the $\mathrm{Cr}(\mathrm{VI})$ concentrations of the $\mathrm{Cr}^{6+}$ solutions before and after incubation with regenerated cells. At least 4 cycles of adsorption-desorption were conducted.

\section{Intrinsic Fluorescence Measurement}

The purified ChrB protein $(10 \mu \mathrm{M}$ in buffer containing $20 \mathrm{mM}$ Tris- $\mathrm{HCl}$ and $0.5 \mathrm{M} \mathrm{NaCl})$ was adjusted to different $\mathrm{pH}$ values $(2,3,4,5,6,7,8,9$ and 10 , respectively) using concentrated $\mathrm{HCl}$ or $\mathrm{NaOH}$. The intrinsic fluorescence of protein samples in different buffer solutions was measured in $2 \mathrm{~mm}$ path-length quartz microcuvettes using the Hitachi F-7000 fluorescence spectrophotometer. After all the samples were neutralized to $\mathrm{pH} \approx 7$, the intrinsic fluorescence of each sample was analyzed again. In addition, the ChrB protein samples $(10 \mu \mathrm{M}$ in buffer containing $20 \mathrm{mM} \mathrm{pH} 7.0$ Tris- $\mathrm{HCl}$ and $0,0.5,1.0,1.5,2.0$, and $2.5 \mathrm{M} \mathrm{NaCl}$, respectively) were also subjected to intrinsic fluorescence measurement. Then, all the protein samples were dialyzed into the buffer without $\mathrm{NaCl}(20 \mathrm{mM}$ Tris-HCl, $\mathrm{pH}$ 7.0) before measuring the intrinsic fluorescence of each sample once more. The emission spectra were monitored from 300 to $500 \mathrm{~nm}$ with the excitation at $280 \mathrm{~nm}$. The spectrum of the buffer solution was used as a blank control.

\section{Results}

Comparison of $\mathrm{Cr}$ (VI) Adsorption Capacity of $E$. coli Expressing Intracellular or Surface-Displayed ChrB

Effective removal of toxic heavy metal ions from the environment using microorganisms is usually achieved by genetic engineering approaches, which can greatly enhance the metal adsorption capacity through overproduction of metal-binding proteins in the cytoplasm or on the cell surface. In this study, we constructed two E. coli strains for the expression of intracellular (pET-ChrB/BL21) and surface-displayed (pET-LOChrB/BL21) ChrB. As shown in Fig. 1, intracellular $\mathrm{ChrB}$ (calculated $\mathrm{MW} \approx 35 \mathrm{kDa}$ ) and surface-displayed ChrB (ChrB fused with the membrane protein $\mathrm{OmpA}$, calculated $\mathrm{MW} \approx 51 \mathrm{kDa}$ ) were both overexpressed, and the identities of the two proteins were confirmed by immunoblot analysis using anti-ChrB antibody. To verify the subcellular localization of $\mathrm{ChrB}$, a protease accessibility experiment was conducted. Because the protease cannot directly permeate through the cell membrane, intracellular proteins would remain intact, whereas those exposed on the cell surface would be digested. Intracellular $\mathrm{ChrB}$ was resistant to $1 \mathrm{~h}$ of protease digestion with trypsin, whereas surface-displayed $\mathrm{ChrB}$ was completely degraded under the same condition (Fig. 1).

To compare the $\mathrm{Cr}(\mathrm{VI})$ adsorption capacities of $E$. coli cells expressing intracellular or surface-displayed ChrB, 


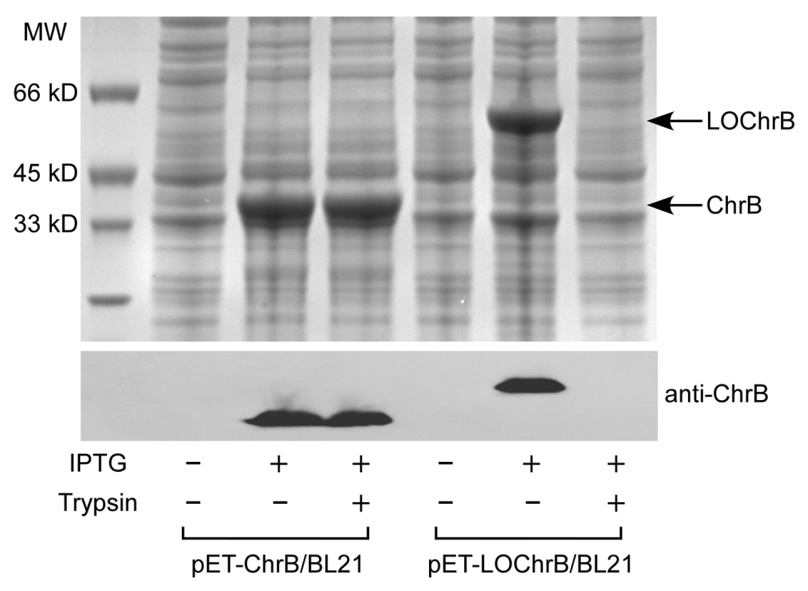

Fig. 1. SDS-PAGE gel (upper panel) and western blot (lower panel) of intracellular and surface-displayed ChrB expressed by pET-ChrB/BL21 and pET-LOChrB/BL21 cells, respectively. Cells were also treated with $100 \mu \mathrm{g} / \mathrm{ml}$ trypsin to verify the subcellular localization of ChrB. Results are representative of three independent experiments.

an equivalent amount of protein yield per cell of both strains should be ensured. Time-course analysis of protein expression by SDS-PAGE and western blotting revealed that the amount of intracellular ChrB produced after $6 \mathrm{~h}$ of induction was approximately equal to that of surface-displayed protein induced after $24 \mathrm{~h}$ for the same cell number (calculated based on the $\mathrm{OD}_{600}$ ), and the maximal protein yields of both cell strains were achieved after $24 \mathrm{~h}$ of induction (Table S2). Next, the $\mathrm{Cr}(\mathrm{VI})$ adsorption capacities of four E. coli cell samples, pET-ChrB-6h/ BL21 (induced for $6 \mathrm{~h}$ ), pET-ChrB-24h/BL21 (induced for $24 \mathrm{~h}$ ), pET-LOChrB/BL21 (induced for $24 \mathrm{~h}$ unless indicated otherwise), and pET/BL21 (induced for $24 \mathrm{~h}$ unless indicated otherwise, used as the negative control), were determined. As shown in Fig. 2, the amount of $\mathrm{Cr}(\mathrm{VI})$ adsorbed increased with increasing concentration of $\mathrm{Cr}(\mathrm{VI})$ for all four cell samples and reached saturation at $2.5 \mathrm{mM} \mathrm{Cr}(\mathrm{VI})$. The maximum $\mathrm{Cr}(\mathrm{VI})$ content adsorbed in the three ChrB-expressing cell samples was significantly higher than that in the control. The maximum $\mathrm{Cr}(\mathrm{VI})$ adsorption capacity of pET-LOChrB/BL21 ( $235 \mu \mathrm{mol} / \mathrm{g}$ cells $)$ was approximately 2.5 - and 1.73 -fold higher than that of pET-ChrB-6h/BL21 and pET-ChrB-24h/BL21, respectively. Although pET-ChrB-24h/BL21 expressed nearly 3 -fold more protein molecules per cell than pET-LOChrB/BL21, its adsorption capacity was only $57.8 \%$ of that of pET-LOChrB/BL21 under the same condition. These results suggested that ChrB expression on the cell surface greatly enhances the $\mathrm{Cr}(\mathrm{VI})$ adsorption capability of $E$. coli cells.

An artificial wastewater sample containing $0.5 \mathrm{mMCr}(\mathrm{VI})$, which is nearly 500 times the maximum permissible limit $(0.05 \mathrm{mg} / \mathrm{l}$ or $0.96 \mu \mathrm{M})$ for $\mathrm{Cr}(\mathrm{VI})$ established by the United States Environmental Protection Agency (US EPA), was used to verify the $\mathrm{Cr}(\mathrm{VI})$ removal capability of E. coli cells expressing ChrB. As shown in Fig. S1, the $\mathrm{Cr}(\mathrm{VI})$ concentration of the water sample was decreased by $24.1 \%, 57.2 \%$, and $99.1 \%$ after $2 \mathrm{~h}$ of treatment with pET-LOChrB/BL21 at an $\mathrm{OD}_{600}$ of 2, 5, and 10, respectively (Fig. S1D), whereas the same numbers of pET-ChrB-

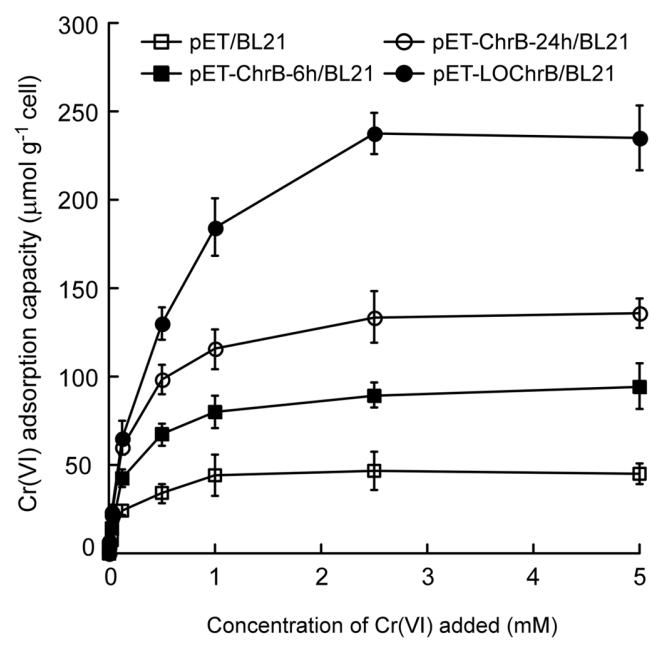

Fig. 2. $\mathrm{Cr}$ (VI) adsorption capacities of E. coli cells expressing surface-displayed ChrB (pET-LOChrB/BL21, induced for $24 \mathrm{~h}$ ), intracellular ChrB (6-h induction for pET-ChrB-6h/BL21 and 24-h induction for pET$\mathrm{ChrB}-24 \mathrm{~h} / \mathrm{BL21})$, and the negative control (pET/BL21). Cells were treated with increasing concentrations of $\mathrm{Cr}^{6+}(0-$ $5 \mathrm{mM}$ ). Data are the means of three independent experiments, error bars represent standard deviation. 
$6 \mathrm{~h} / \mathrm{BL} 21$ cells could remove only $19.4 \%, 28.0 \%$, and $42.9 \%$ of the total $\mathrm{Cr}(\mathrm{VI})$ at maximum, respectively (Fig. S1B). The above results demonstrate that $E$. coli cells expressing surface-displayed $\mathrm{ChrB}$ are more effective in $\mathrm{Cr}(\mathrm{VI})$ adsorption and removal from aqueous solutions than those harboring intracellular ChrB.

Additionally, the $\mathrm{Cr}(\mathrm{III})$ contents of the treated water samples were tested. As shown in Fig. S2, there were no significant differences in $\mathrm{Cr}$ (III) produced between the supernatant samples after treatment with pET-LOChrB/ BL21, pET-ChrB-24h/BL21, and pET/BL21 (17.9\%, 16.4\%, 15.6\% of the original Cr(VI) content, respectively). The reduction of $\mathrm{Cr}(\mathrm{VI})$ to $\mathrm{Cr}(\mathrm{III})$ is attributed to various reductases present in the $E$. coli cells $[12,13]$ rather than the overexpression of $\mathrm{ChrB}$. The results suggest that the removal of $\mathrm{Cr}(\mathrm{VI})$ by $\mathrm{ChrB}$-engineered E. coli cells was mainly due to $\mathrm{Cr}(\mathrm{VI})$ adsoption rather than $\mathrm{Cr}(\mathrm{VI})$ reduction.

\section{Comparison of $\mathrm{Cr}(\mathrm{VI})$ Resistance of $E$. coli Expressing Intracellular or Surface-Displayed ChrB}

Generally, enhanced biosorption through overproduction of metal-binding proteins results in higher cellular tolerance to toxic metals [14]. This renders bioadsorbents more applicable for the treatment of industrial effluents, which usually contain high concentrations of heavy metals. To compare $\mathrm{Cr}(\mathrm{VI})$ resistance of $E$. coli expressing intracellular or surface-displayed ChrB, their growth in LB medium supplemented with increasing concentrations of $\mathrm{Cr}(\mathrm{VI})$ was monitored. As shown in Fig. 3, in the absence of $\mathrm{Cr}(\mathrm{VI})$, induction of intracellular as well as surface-displayed ChrB inhibited the growth of E. coli strains compared to that of the negative control, likely because the cells allocated energy to protein overexpression that could have been otherwise be used for cell proliferation. A low level of $\mathrm{Cr}(\mathrm{VI})(<10 \mu \mathrm{M})$ to the medium did not inhibit the growth of any of the strains. At $\mathrm{Cr}(\mathrm{VI})$ concentrations above $100 \mu \mathrm{M}$, cells expressing $\mathrm{ChrB}$ were more resistant to $\mathrm{Cr}(\mathrm{VI})$ toxicity than control cells. The minimal inhibitory concentrations (MICs) were $1 \mathrm{mM}$ for pET/BL21, 2.5 $\mathrm{mM}$ for pET-ChrB/BL21, and $5 \mathrm{mM}$ for pET-LOChrB/BL21 cells, suggesting that $\mathrm{Cr}(\mathrm{VI})$ resistance decreases in the following order: pET$\mathrm{LOChrB} / \mathrm{BL} 21>\mathrm{pET}-\mathrm{ChrB} / \mathrm{BL} 21>\mathrm{pET} / \mathrm{BL} 21$. The increase in $\mathrm{Cr}(\mathrm{VI})$ resistance in the engineered strains can be attributed to the binding of $\mathrm{Cr}(\mathrm{VI})$ to $\mathrm{ChrB}$ and the concomitant alleviation of chromium stress in the cells. These results corroborate the finding that surface-displayed $\mathrm{ChrB}$ is more effective in $\mathrm{Cr}(\mathrm{VI})$ adsorption than intracellular ChrB.

Effect of $\mathrm{pH}$ and Salinity on the $\mathrm{Cr}(\mathrm{VI})$ Adsorption Capacity of E. coli Expressing Intracellular or SurfaceDisplayed ChrB

Acidity $(\mathrm{pH})$ considerably influences metal binding by affecting metal speciation and the structural conformation of metal-binding proteins $[15,16]$. Moreover, as industrial wastewater often contains a large amount of dissolved inorganic/organic matter, the effect of other environmental factors, such as ionic strength, should also be evaluated. Thus, $\mathrm{Cr}(\mathrm{VI})$ adsorption was tested across a wide range of $\mathrm{pH}$ values $(2-10)$ and $\mathrm{NaCl}$ concentrations $(0-1.4 \mathrm{M})$. Fig. $4 \mathrm{~A}$ depicts the $\mathrm{pH}$ profile of $\mathrm{Cr}(\mathrm{VI})$ adsorption by cells with intracellular (pETChrB-24h/BL21) and surface-displayed (pET-LOChrB/BL21) ChrB. The adsorption capacity of pET-LOChrB/ BL21 peaked at $\mathrm{pH} 6.0$, and dramatically decreased under acidic conditions $(\mathrm{pH}<4)$. Increased $\mathrm{pH}(\mathrm{pH}>8)$ also attenuated the $\mathrm{Cr}(\mathrm{VI})$ adsorption capacity. In contrast, $\mathrm{Cr}(\mathrm{VI})$ adsorption of pET-ChrB-24h/BL21 changed by less than $14.1 \%$ (coefficient of variation) over the $\mathrm{pH}$ range tested. $\mathrm{Cr}(\mathrm{VI})$ adsorption by $\mathrm{pET}-\mathrm{LOChrB} / \mathrm{BL} 21$ began to gradually decrease in the presence of $\mathrm{NaCl}$ at concentrations starting from $0.6 \mathrm{M}$, whereas $\mathrm{Cr}(\mathrm{VI})$ adsorption by pET-ChrB-24h/BL21 remained nearly the same at $\mathrm{NaCl}$ concentrations of $0-1.2 \mathrm{M}$ and decreased by only $17.1 \%$ at $1.4 \mathrm{M}$ (Fig. 4B). These results suggest that $E$. coli cells expressing intracellular $\mathrm{ChrB}$ are more resistant to low $\mathrm{pH}$ and high ionic strength than cells with surface-displayed $\mathrm{ChrB}$. It should be noted that $\mathrm{Cr}(\mathrm{VI})$ adsorption by pETChrB-24h/BL21 was higher than that of $\mathrm{pET}-\mathrm{LOChrB} / \mathrm{BL} 21$ at $\mathrm{pH} \leq 3.0$ or $\mathrm{NaCl} \geq 1.2 \mathrm{M}$.

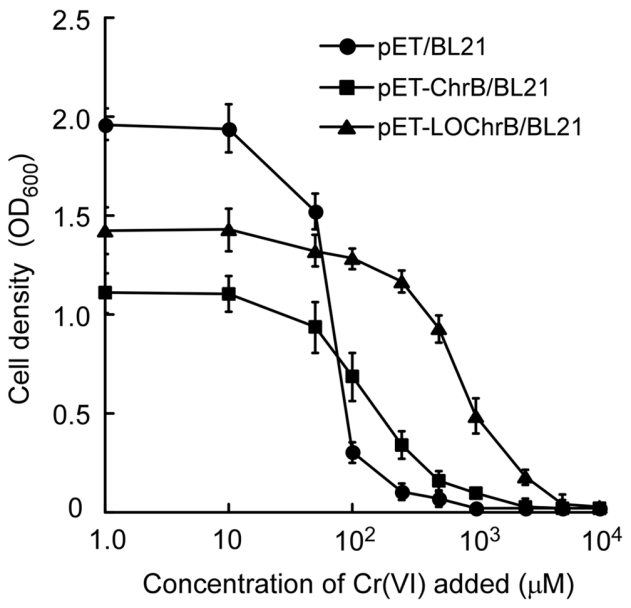

Fig. 3. Growth of pET/BL21, pET-ChrB/BL21, and pET-LOChrB/BL21 E. coli cells in LB medium with increasing concentrations of $\mathrm{Cr}(\mathrm{VI})(0.001-10 \mathrm{mM})$ in the presence of $100 \mu \mathrm{M}$ IPTG. The cell samples were adjusted to $\mathrm{OD}_{600}=0.02$ and then cultured at $25^{\circ} \mathrm{C}$ for $12 \mathrm{~h}$ before the $\mathrm{OD}_{600}$ was measured again. Data are means of three independent experiments, error bars represent standard deviation. 

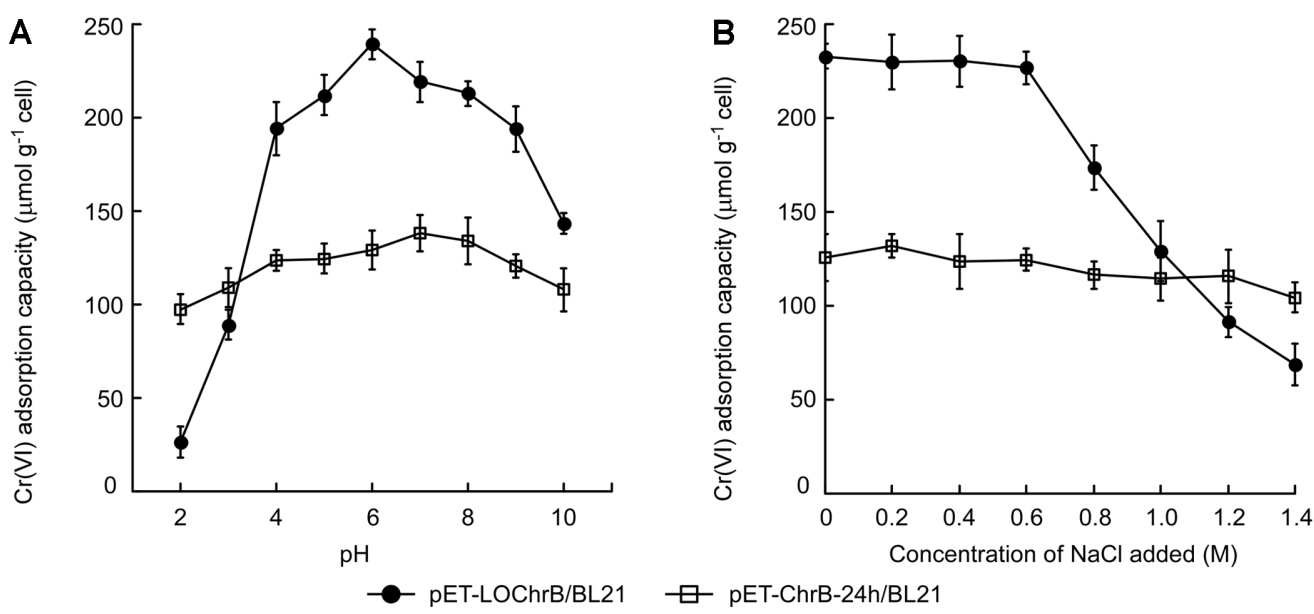

Fig. 4. (A) Effect of $\mathrm{pH}(2-10)$ on the $\mathrm{Cr}(\mathrm{VI})$ adsorption capacity of $E$. coli cells expressing surface-displayed ChrB (pET-LOChrB/BL21) or intracellular ChrB (pET-ChrB-24h/BL21). (B) Effect of ionic strength (0-1.4 M $\mathrm{NaCl}$ ) on the $\mathrm{Cr}(\mathrm{VI})$ adsorption capacity of $E$. coli cells expressing surface-displayed ChrB (pET-LOChrB/BL21) or intracellular ChrB (pET-ChrB-24h/BL21). Data are means of three independent experiments, error bars represent standard deviation.

Removal of $\mathrm{Cr}(\mathrm{VI})$ from Industrial Wastewater Samples by E. coli Expressing Intracellular or SurfaceDisplayed ChrB

To evaluate the applicability of engineered $E$. coli cells for the removal of $\mathrm{Cr}(\mathrm{VI})$ from authentic industrial effluents, they were tested using 12 wastewater samples obtained from tanneries or chromium electroplating factories. As shown in Table S3, all samples contained high levels of $\mathrm{Cr}(\mathrm{VI})$, at varying concentrations. After treatment with pET-ChrB-24h/BL21 and pET-LOChrB/BL21 $\left(\mathrm{OD}_{600}=50\right)$, the initial $\mathrm{Cr}(\mathrm{VI})$ contents of the samples decreased significantly to different extents. The slight decrease in $\mathrm{Cr}$ (III) was probably due to the intrinsic ability of the microorganisms to adsorb diverse metal ions in a non-specific manner [17], because ChrB was found to inefficiently bind Cr(III) (Fig. S3). Consistent with the results in Fig. 4A, pET-LOChrB/BL21 adsorbed more $\mathrm{Cr}(\mathrm{VI})$ than $\mathrm{pET}-\mathrm{ChrB}-24 \mathrm{~h} / \mathrm{BL} 21$ at $\mathrm{pH}>4$, whereas it was less effective in $\mathrm{Cr}(\mathrm{VI})$ removal from highly acidic wastewater samples $(\mathrm{pH}<3)$. Compared to TDS, $\mathrm{pH}$ strongly affected $\mathrm{Cr}(\mathrm{VI})$ adsorption by the engineered E. coli cells. These results suggest that for effective removal of $\mathrm{Cr}(\mathrm{VI})$ from industrial effluents, the use of either intracellular or surface-displayed ChrB-expressing strains should depend on the $\mathrm{pH}$ of the samples to be treated.

Desorption of $\mathrm{Cr}(\mathrm{VI})$ and Regeneration of E. coli Expressing Intracellular or Surface-Displayed ChrB

Regeneration/reuse of the bioadsorbent is usually very important with respect to both resource recovery and continuous biomass supply. Therefore, it is necessary to evaluate the regeneration ability of $E$. coli expressing intracellular or surface-displayed ChrB. The adsorption process should be followed by contaminant desorption, therefore desorption experiments using $\mathrm{Cr}(\mathrm{VI})$-bound $E$. coli cells with intracellular or surface-displayed ChrB
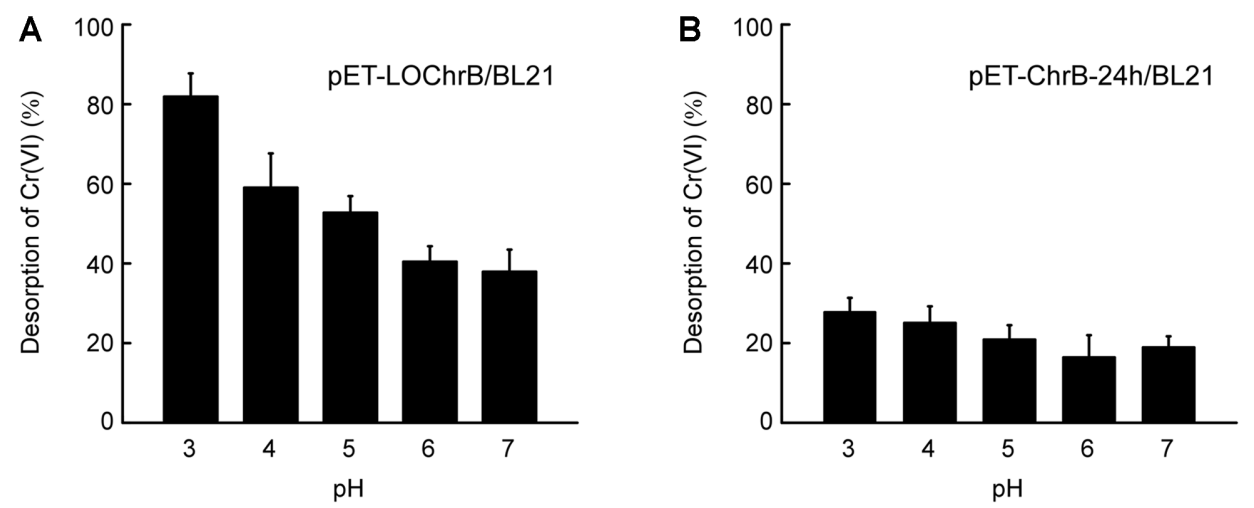

Fig. 5. Effect of pH on $\mathrm{Cr}(\mathrm{VI})$ desorption from $\mathrm{Cr}$ (VI)-bound pET-LOChrB/BL21 or pET-ChrB-24h/BL21 $\left(\mathrm{OD}_{600}=10\right)$ pretreated with $5 \mathrm{mM} \mathrm{C \mathbf {r } ^ { 6 + }}$. After at least two washes with Tris buffers of varying $\mathrm{pH}(3,4,5,6$, and 7$)$, the total $\mathrm{Cr}(\mathrm{VI})$ content in each cell pellet was measured. $\mathrm{Cr}(\mathrm{VI})$ desorption was calculated as the difference between the total $\mathrm{Cr}(\mathrm{VI})$ content of the $\mathrm{Cr}(\mathrm{VI})$-treated cells before and after washing. Data are the means of three independent experiments, error bars represent the standard deviation. 

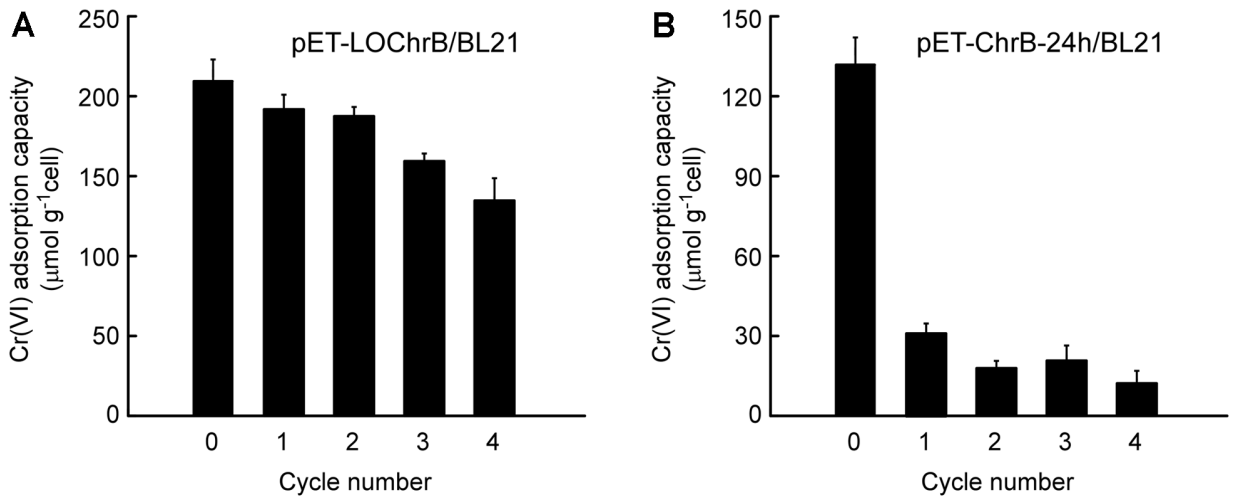

Fig. 6. Regeneration ability of pET-LOChrB/BL21 and pET-ChrB-24h/BL21 after successive cycles of Cr(VI) adsorption and desorption. Cells $\left(\mathrm{OD}_{600}=10\right)$ pretreated with $5 \mathrm{mM} \mathrm{Cr}^{6+}$ were washed with Tris buffer $(\mathrm{pH}=3.0)$ at least twice to release $\mathrm{Cr}(\mathrm{VI})$ and were then treated with $5 \mathrm{mM} \mathrm{Cr}^{6+}$ to evaluate their regeneration ability. $\mathrm{The} \mathrm{Cr}(\mathrm{VI})$ adsorption capacity of the regenerated cells was calculated as the difference between the $\mathrm{Cr}(\mathrm{VI})$ concentrations of the $\mathrm{Cr}^{6+}$ solutions before and after treatment with regenerated cells at the end of each of the 4 cycles. Cycle 0 represents freshly prepared cells. Data are the means of three independent experiments, error bars represent the standard deviation.

were performed in Tris buffers of varying $\mathrm{pH}$. As shown in Fig. 5, approximately $37.4 \%$ and $18.5 \% \mathrm{Cr}(\mathrm{VI})$ was released from pET-LOChrB/BL21 and pET-ChrB-24h/BL21 at pH 7.0, respectively. However, when the pH was decreased to 3.0, nearly $81.3 \% \mathrm{Cr}(\mathrm{VI})$ was desorbed from pET-LOChrB/BL21 (Fig. 5A), whereas only $27.1 \%$ $\mathrm{Cr}(\mathrm{VI})$ was desorbed from pET-ChrB-24h/BL21 under the same condition (Fig. 5B). As biomass would get denatured when treated with strong acid $(\mathrm{pH}<2.0), \mathrm{pH} 3.0$ was used to desorb $\mathrm{Cr}(\mathrm{VI})$ and regenerate the E. coli cells. Compared to freshly cultured pET-LOChrB/BL21, only a slight loss $(<25 \%)$ in adsorption capacity was observed in regenerated cells during the first three adsorption-desorption cycles, and $64.7 \%$ binding capacity was retained at the end of the fourth cycle (Fig. 6A). In contrast, pET-ChrB-24h/BL21 could not be effectively regenerated; the $\mathrm{Cr}(\mathrm{VI})$ adsorption capacity decreased to only $23.9 \%$ when reused (Fig. $6 \mathrm{~B}$ ). These results demonstrate that compared with intracellular accumulation, cell-surface adsorption is reversible, which allows easy desorption of the adsorbed metal ions and regeneration of the bioadsorbent.

Effect of $\mathrm{pH}$ and Salinity on the Protein Conformation of Purified ChrB

To explain the effect of $\mathrm{pH}$ and salinity on the $\mathrm{Cr}(\mathrm{VI})$ adsorption capacity of $E$. coli expressing intracellular or surface-displayed $\mathrm{ChrB}$, the intrinsic fluorescence emission of purified $\mathrm{ChrB}$ protein under different $\mathrm{pH}$ or salinity conditions was measured to monitor protein conformational changes. As shown in Fig. 7, the intrinsic fluorescence of $\mathrm{ChrB}$ protein was not significantly altered in the $\mathrm{pH}$ range of 4 to 9 , and decreased by $23.1 \%$ or
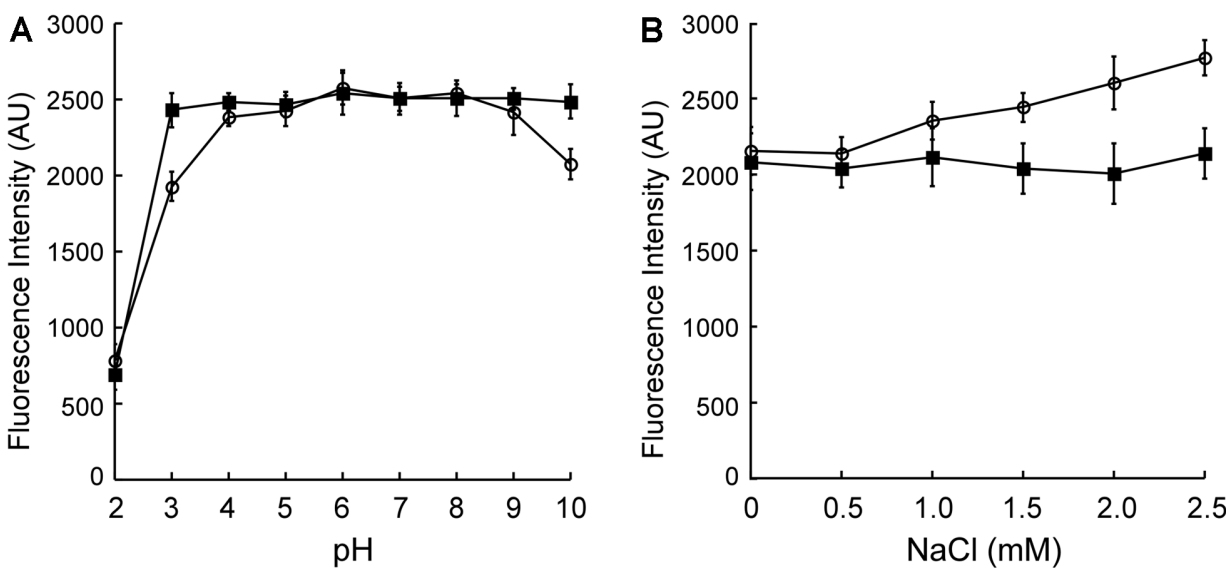

Fig. 7. Effect of $\mathbf{p H}$ and salinity on the protein conformation of purified ChrB. (A) The purified ChrB protein $(10 \mu \mathrm{M})$ in buffer was adjusted to different $\mathrm{pH}$ values before the intrinsic fluorescence of protein samples was measured (hollow circle). After all the samples were neutralized to $\mathrm{pH} \approx 7$, the intrinsic fluorescence of each sample was analyzed again (filled square). (B) The ChrB protein samples ( $10 \mu \mathrm{M}$ in buffer containing $20 \mathrm{mM} \mathrm{pH} 7.0$ Tris- $\mathrm{HCl}$ and $0,0.5,1.0,1.5,2.0$, and $2.5 \mathrm{M}$ $\mathrm{NaCl}$, respectively) were also subjected to intrinsic fluorescence measurement (hollow circle). Then, all the protein samples were dialyzed into the buffer without $\mathrm{NaCl}(20 \mathrm{mM}$ Tris- $\mathrm{HCl}, \mathrm{pH}$ 7.0) before measuring the intrinsic fluorescence of each sample once more (filled square). The emission spectra were monitored from 300 to $500 \mathrm{~nm}$ with the excitation at $280 \mathrm{~nm}$. Data are the means of three independent experiments, error bars represent the standard deviation. 
$17.3 \%$ at $\mathrm{pH} 3$ or 10 , respectively. However, at $\mathrm{pH}$ below 2 , the protein was denatured, with the formation of visible white precipitates, and the intrinsic fluorescence intensity decreased dramatically. When the samples were subsequently neutralized, the intrinsic fluorescence of the acid- or alkali-treated protein samples recovered, except for the sample with $\mathrm{pH}$ 2, because the proteins in this sample had been irreversibly denatured. Similarly, we tested the intrinsic fluorescence of $\mathrm{ChrB}$ in the presence of increasing concentrations of $\mathrm{NaCl}$, and we found that it gradually increased. After the removal of $\mathrm{NaCl}$, the intrinsic fluorescence of all the $\mathrm{NaCl}$-treated protein samples was restored. These results suggest that $\mathrm{pH}$ and salinity may influence the $\mathrm{Cr}(\mathrm{VI})$ adsorption capacity of E. coli expressing surface-displayed ChrB by modulating the protein conformation of $\mathrm{ChrB}$.

\section{Discussion}

Among the toxic heavy metals present in industrial wastewaters, chromium, especially $\mathrm{Cr}(\mathrm{VI})$, is considered extremely harmful. Therefore, effective removal of $\mathrm{Cr}(\mathrm{VI})$ is of vital importance. Because physicochemical methods are energy- and cost-intensive and result in the generation of secondary pollution, relevant biological treatment (bioremediation) techniques have garnered increasing attention.

Many microorganisms are capable of removing chromate ions [18]. There are two main types of bioremediation strategies utilized to treat $\mathrm{Cr}(\mathrm{VI})$-contaminated wastewaters, biosorption and bioreduction. Biosorption is the removal of $\mathrm{Cr}(\mathrm{VI})$ ions from aqueous solutions by direct binding to bioadsorbents, whereas bioreduction involves the transformation of $\mathrm{Cr}(\mathrm{VI})$ to $\mathrm{Cr}(\mathrm{III})$, without altering the total amount of chromium. Biosorption has several advantages over bioreduction. First, biosorption is usually very fast and can be completed in a short time. For example, Bacillus coagulans was reported to adsorb 30.7-40.6 mg Cr(VI)/g dry weight within 1-2 h [19], and Lantana camara plants reportedly removed $98 \%$ of $\mathrm{Cr}(\mathrm{VI})$ from wastewater (initial concentration $=50 \mathrm{mg} / \mathrm{l}$ ) in 30 min [20]. In this study, surface-displayed ChrB rapidly removed $99.1 \%$ of the total $\mathrm{Cr}(\mathrm{VI})$ in $2 \mathrm{~h}$ (Fig. S1). However, reduction of $\mathrm{Cr}(\mathrm{VI})$ to $\mathrm{Cr}(\mathrm{III})$ generally takes more than $24 \mathrm{~h}$ [21]. Further, reduced $\mathrm{Cr}$ (III) in wastewater can be re-oxidized to $\mathrm{Cr}(\mathrm{VI})$ under various conditions, for example, during chlorination of drinking water [22] or in chromium-contaminated sludge [23]. Therefore, $\mathrm{Cr}(\mathrm{VI})$ removal by biosorption is safer than bioreduction as it completely eliminates the risk of $\mathrm{Cr}$ (III) oxidization.

The efficiency of bacterial bioremediation can be increased in various ways. Genetic engineering can be utilized to enhance chromate adsorption or $\mathrm{Cr}(\mathrm{VI})$ reduction based on $\mathrm{Cr}(\mathrm{VI})$ resistance mechanisms. $\mathrm{The} \operatorname{Cr}(\mathrm{VI})$ removal capabilities of the two E. coli strains engineered in this study were compared with respect to maximal adsorption capacity, adsorption efficiency, effect of $\mathrm{pH}$, and salinity. The maximal adsorption capacity of pETLOChrB/BL21 was about $235 \mu \mathrm{mol} \mathrm{Cr}(\mathrm{VI}) / \mathrm{g}$ dry weight, which is comparable to that of previously reported $\mathrm{Cr}(\mathrm{VI})$ bioadsorbents [24]. pET-LOChrB/BL21 cells removed nearly all $\mathrm{Cr}$ (VI) from wastewater (initial concentration $=0.5 \mathrm{mM}$ ) in $2 \mathrm{~h}$, whereas the saturation point of adsorption with pET-ChrB-24h/BL21 occurred at 3-4 h, with only $42.9 \%$ of total $\mathrm{Cr}(\mathrm{VI})$ eliminated (Fig. S1). This is because intracellular adsorption requires transport of the metal ions across the cell membrane, and excess intracellular $\mathrm{Cr}(\mathrm{VI})$ would be exported out of the cell via resistance mechanisms [5]. Therefore, surface-displayed ChrB is substantially more effective for $\mathrm{Cr}(\mathrm{VI})$ adsorption than cytoplasmic expression under normal conditions.

However, effluents from the chromium electroplating industries are usually extremely acidic, with high levels of TDS. The data in Table S3 indicate that, under such conditions, $\mathrm{Cr}(\mathrm{VI})$ removal by pET-ChrB-24h/BL21 was greater than that by $\mathrm{pET}-\mathrm{LOChrB} / \mathrm{BL} 21$. It has been suggested that $\mathrm{Cr}(\mathrm{VI})$ in aqueous solution can form several species, such as $\mathrm{Cr}_{2} \mathrm{O}_{7}^{2-}, \mathrm{CrO}_{4}^{2-}$, and $\mathrm{HCrO}_{4}^{-}$, which may have diverse protein-binding affinities. Speciation of $\mathrm{Cr}(\mathrm{VI})$ mainly depends on the $\mathrm{pH}$ of the solution [15]; thus, $\mathrm{pH}$ can influence $\mathrm{Cr}(\mathrm{VI})$ biosorption. More importantly, $\mathrm{pH}$ may influence metal binding by affecting the structural conformation of metal-binding proteins [16]. Our results also show that the $\mathrm{pH}$ and salinity can influence the protein conformation of ChrB (Fig. 7). However, E. coli cells can regulate cytoplasmic $\mathrm{pH}$ to protect biomolecules from extremely acidic or alkaline extracellular conditions [25]. The intracellular $\mathrm{pH}$ homeostasis of $E$. coli was attributed to $\mathrm{pH}$-dependent catabolism and ion fluxes [26]. Furthermore, bacteria have evolved numerous systems to survive under high levels of salinity, which are responsible for metal homeostasis and resistance [27]. In this scenario, intracellular metal-binding proteins would be less susceptible to external variation in $\mathrm{pH}$ or ionic strength than surface-displayed proteins.

It should be noted that purified $\mathrm{ChrB}$ protein had a very weak binding affinity for $\mathrm{Cr}(\mathrm{VI})$ in vitro. The purified ChrB was treated with 10 -fold excess of $\mathrm{Cr}(\mathrm{VI})$ solution and then repurified using a desalting column. $\mathrm{Cr}(\mathrm{VI})$ content analysis showed that each $\mathrm{ChrB}$ protein monomer could bind less than $1 / 10$ th molecule of $\mathrm{Cr}(\mathrm{VI})$. As purified ChrB protein reportedly can form oligomers (mainly dimers) [9], the putative chromate-binding residues (Arg180, Arg187, His229) were probably embedded upon oligomerization after the protein was purified from $E$. coli cells under aerobic condition. Thus, we attempted to reconstitute the purified $\mathrm{ChrB}$ with $\mathrm{Cr}(\mathrm{VI})$ in the presence of DTT, which reduced the protein to its monomeric form. However, DTT-treated ChrB still could not significantly bind $\mathrm{Cr}(\mathrm{VI})$, because the DTT also reduced $\mathrm{Cr}(\mathrm{VI})$ to $\mathrm{Cr}(\mathrm{III})$, which hardly has a binding affinity for $\mathrm{ChrB}$ (Fig. S3). Although oligomer formation can hinder purified ChrB from binding $\mathrm{Cr}(\mathrm{VI})$ in vitro, the majority of the proteins should be in the monomeric form in vivo, because reductases, e.g., enzymes of the thioredoxin antioxidant system [13] and glutathione reductase [28], are ubiquitously present in the cell. This was supported by the observation that approximately one molecule $(1.13 \pm 0.09)$ of $\mathrm{Cr}(\mathrm{VI})$ was detected in each His-tagged ChrB monomer when purified from $E$. coli cells that were pretreated with $5 \mathrm{mM} \mathrm{Cr}(\mathrm{VI})$, suggesting that $\mathrm{ChrB}$ is capable of binding $\mathrm{Cr}(\mathrm{VI})$ in vivo. Furthermore, fusion of $\mathrm{ChrB}$ to OmpA may avoid multimerization because the chimeric protein with a tightly folded conformation cannot be transported across the outer membrane [29], implying that $\mathrm{ChrB}$ displaying on the cell surface should be in the monomeric form. As the amount of intracellular $\mathrm{ChrB}$ produced after $6 \mathrm{~h}$ of induction was similar to that of surface-displayed protein after 24 -h induction for the 
same cell number (Table S2), surface-displayed ChrB is estimated to bind approximately four atoms (4.25 \pm 0.37$)$ of $\mathrm{Cr}(\mathrm{VI})$ at maximum. While further investigations are required to elucidate the biochemical properties of $\mathrm{ChrB}$ and other metal-adsorbing proteins, our study provided useful strategies for the engineering of microorganisms to remove heavy metal pollutants.

\section{Acknowledgment}

This work was supported by the National High Technology Research and Development Program of China (2014AA06A514), the Zhejiang Province Public Welfare Technology Application Research Project (LGF20B070001), the Natural Science Foundation of Zhejiang Province (LY13C050003), the Key Discipline of Zhejiang Province in Medical Technology (First Class, Category A), and the Science and Technology Project of Wenzhou (S20170016).

\section{Conflict of Interest}

The authors have no financial conflicts of interest to declare.

\section{References}

1. Ke C, Zhao C, Rensing C, Yang S, Zhang Y. 2018. Characterization of recombinant E. coli expressing arsR from Rhodopseudomonas palustris CGA009 that displays highly selective arsenic adsorption. Appl. Microbiol. Biotechnol. 102: 6247-6255.

2. Li H, Cong Y, Lin J, Chang Y. 2015. Enhanced tolerance and accumulation of heavy metal ions by engineered Escherichia coli expressing Pyrus calleryana phytochelatin synthase. J. Basic Microbiol. 55: 398-405.

3. Wang W, Jiang F, Wu F, Li J, Ge R, Tan G, et al. 2019. Biodetection and bioremediation of copper ions in environmental water samples using a temperature-controlled, dual-functional Escherichia coli cell. Appl. Microbiol. Biotechnol. 103: 6797-6807.

4. Yin K, Lv M, Wang Q, Wu Y, Liao C, Zhang W, et al. 2016. Simultaneous bioremediation and biodetection of mercury ion through surface display of carboxylesterase E2 from Pseudomonas aeruginosa PA1. Water Res. 103: 383-390.

5. Ramirez-Diaz MI, Diaz-Perez C, Vargas E, Riveros-Rosas H, Campos-Garcia J, Cervantes C. 2008. Mechanisms of bacterial resistance to chromium compounds. Biometals 21: 321-332.

6. Branco R, Alpoim MC, Morais PV. 2004. Ochrobactrum tritici strain 5bvl1 - characterization of a $\mathrm{Cr}(\mathrm{VI})$-resistant and Cr(VI)reducing strain. Can. J. Microbiol. 50: 697-703.

7. Branco R, Chung AP, Johnston T, Gurel V, Morais P, Zhitkovich A. 2008. The chromate-inducible chrBACF operon from the transposable element ThOtChr confers resistance to chromium(VI) and superoxide. J. Bacteriol. 190: 6996-7003.

8. Branco R, Morais PV. 2016. Two superoxide dismutases from TnOtchr are involved in detoxification of reactive oxygen species induced by chromate. BMC Microbiol. 16: 27.

9. Branco R, Morais PV. 2013. Identification and characterization of the transcriptional regulator ChrB in the chromate resistance determinant of Ochrobactrum tritici 5bvl1. PLoS One 8: e77987.

10. Bregnbak D, Johansen JD, Jellesen MS, Zachariae C, Thyssen JP. 2015. Chromium(VI) release from leather and metals can be detected with a diphenylcarbazide spot test. Contact Dermatitis 73: 281-288.

11. Aniyikaiye TE, Oluseyi T, Odiyo JO, Edokpayi JN. 2019. Physico-chemical analysis of wastewater discharge from selected paint industries in lagos, Nigeria. Int. J. Environ. Res. Public Health 16: 1235.

12. Rapisarda VA, Montelongo LR, Farias RN, Massa EM. 1999. Characterization of an NADH-linked cupric reductase activity from the Escherichia coli respiratory chain. Arch. Biochem. Biophys. 370: 143-150.

13. Lu J, Holmgren A. 2014. The thioredoxin antioxidant system. Free Radical Biol. Med. 66: 75-87.

14. Kuroda K, Ueda M. 2006. Effective display of metallothionein tandem repeats on the bioadsorption of cadmium ion. Appl. Microbiol. Biotechnol. 70: 458-463.

15. Barrera-Diaz CE, Lugo-Lugo V, Bilyeu B. 2012. A review of chemical, electrochemical and biological methods for aqueous Cr(VI) reduction. J. Hazard. Mater. 223-224: 1-12.

16. Thakur G, Jiang K, Lee D, Prashanthi K, Kim S, Thundat T. 2014. Investigation of pH-induced protein conformation changes by nanomechanical deflection. Langmuir 30: 2109-2116.

17. Ayangbenro AS, Babalola OO. 2017. A new strategy for heavy metal polluted environments: a review of microbial biosorbents. Int. J. Environ. Res. Public Health. 14: 94.

18. Joutey NT, Sayel H, Bahafid W, El Ghachtouli N. 2015. Mechanisms of hexavalent chromium resistance and removal by microorganisms. Rev. Environ. Contam. Toxicol. 233: 45-69.

19. Srinath T, Garg SK, Ramteke PW. 2003. Biosorption and elution of chromium from immobilized Bacillus coagulans biomass. Indian J. Exp. Biol 41: 986-990.

20. Ravulapalli S, Kunta R. 2018. Enhanced removal of chromium (VI) from wastewater using active carbon derived from Lantana camara plant as adsorbent. Water Sci. Technol. 78: 1377-1389.

21. Malaviya P, Singh A. 2016. Bioremediation of chromium solutions and chromium containing wastewaters. Crit. Rev. Microbiol. 42: 607-633.

22. Lindsay DR, Farley KJ, Carbonaro RF. 2012. Oxidation of Cr(III) to Cr(VI) during chlorination of drinking water. J. Environ. Monit. 14: $1789-1797$.

23. Apte AD, Tare V, Bose P. 2006. Extent of oxidation of $\mathrm{Cr}(\mathrm{III})$ to $\mathrm{Cr}(\mathrm{VI})$ under various conditions pertaining to natural environment. J. Hazard. Mater. 128: 164-174.

24. Garg SK, Tripathi M, Srinath T. 2012. Strategies for chromium bioremediation of tannery effluent. Rev. Environ. Contam. Toxicol. 217: $75-140$

25. Slonczewski JL, Rosen BP, Alger JR, Macnab RM. 1981. pH homeostasis in Escherichia coli: measurement by 31P nuclear magnetic resonance of methylphosphonate and phosphate. Proc. Natil Acad. Sci. USA 78: 6271-6275.

26. Kitko RD, Wilks JC, Garduque GM, Slonczewski JL. 2010. Osmolytes contribute to pH homeostasis of Escherichia coli. PLoS One 5: e10078.

27. Chandrangsu P, Rensing C, Helmann JD. 2017. Metal homeostasis and resistance in bacteria. Nature Rev. Microbiol. 15: 338-350

28. Couto N, Wood J, Barber J. 2016. The role of glutathione reductase and related enzymes on cellular redox homoeostasis network. Free Radic. Biol. Med. 95: 27-42.

29. Stathopoulos C, Georgiou G, Earhart CF. 1996. Characterization of Escherichia coli expressing an Lpp'OmpA(46-159)-PhoA fusion protein localized in the outer membrane. Appl. Microbiol. Biotechnol. 45: 112-119. 